\title{
Erratum to: Performance of ultralow-dose CT with iterative reconstruction in lung cancer screening: limiting radiation exposure to the equivalent of conventional chest $\mathrm{X}$-ray imaging
}

\author{
Adrian Huber ${ }^{1,2} \cdot$ Julia Landau $^{1} \cdot$ Lukas Ebner $^{1,3}$ - Yanik Bütikofer ${ }^{1} \cdot$ Lars Leidolt $^{1}$ \\ Barbara Brela $^{1} \cdot$ Michelle May $^{1} \cdot$ Johannes Heverhagen $^{1} \cdot$ Andreas Christe $^{1}$
}

Published online: 5 April 2016

(C) European Society of Radiology 2016

Erratum to: Eur Radiol

DOI 10.1007/s00330-015-4192-3

The given names and family names of all authors were transposed in the original publication, but have since been corrected.

The corrected names are:

Adrian Huber, Julia Landau, Lukas Ebner, Yanik Bütikofer, Lars Leidolt, Barbara Brela, Michelle May, Johannes Heverhagen, Andreas Christe

The online version of the original article can be found at http:// dx.doi.org/10.1007/s00330-015-4192-3.

\section{Adrian Huber}

adrian.huber@insel.ch

1 Department of Diagnostic, Interventional and Paediatric Radiology, University Hospital Inselspital Bern, CH-3010 Bern, Switzerland

2 Department of Polyvalent and Oncological Radiology, University Hospital Pitié-Salpêtrière, Paris, France

3 Department of Radiology, Duke University Medical Center, Durham, NC, USA 